\title{
Predictive factors in the treatment of streptococcal endophthalmitis
}

This article was published in the following Dove Press journal:

Clinical Ophthalmology

\author{
Yosanan Yospaiboon \\ Kidakarn Meethongkam \\ Suthasinee Sinawat \\ Wipada Laovirojjanakul \\ Tanapat Ratanapakorn \\ Thuss Sanguansak \\ Chavakij Bhoomibunchoo \\ KKU Eye Center, Department of \\ Ophthalmology, Faculty of Medicine, \\ Khon Kaen University, Khon Kaen, \\ Thailand
}

\begin{abstract}
Objective: To evaluate visual outcomes and possible predictive factors in the treatment of infectious endophthalmitis caused by Streptococcus species during 2012-2016 at a large referral eye center in northeastern Thailand.

Methods: A retrospective medical record chart review of patients with culture-positive endophthalmitis caused by Streptococcus species was conducted. Demographic data including age, gender, occupation, duration of symptoms, time to surgery, surgical procedures, initial visual acuity at presentation, and final visual acuity after treatment were collected and analyzed. Possible predictive factors associated with improved visual outcomes were also studied.

Results: Forty-five eyes of 45 patients were recruited for the study. The 3 most common types of endophthalmitis were postoperative $(35.56 \%)$, posttraumatic $(20 \%)$, and endogenous (15.56\%). At presentation, most patients $(95.56 \%)$ had visual acuity of hand motion $(55.56 \%)$, light perception (28.89\%), or no light perception (11.11\%). The 3 most common isolates were Streptococcus pneumoniae (44.44\%), Group B $\beta$-hemolytic Streptococcus (26.68\%), and Streptococcus viridans (20\%). Most patients (62.22\%) were treated with surgical interventions, either pars plana vitrectomy with intravitreal antibiotics or pars plana vitrectomy with intravitreal antibiotics and silicone oil tamponade. After treatment, improved visual outcome was noted in only 9 patients (20\%), and no visual improvement was seen in 36 patients (80\%). Evisceration and enucleation were performed in 15 patients (33.33\%). The only possible predictive factor associated with improved visual outcomes was early vitrectomy, performed within 3 days.

Conclusion: Streptococcal endophthalmitis is often associated with poor visual prognosis. Only 9 patients $(20 \%)$ had improved vision after treatment. The only possible predictive factor associated with improved visual outcomes was vitrectomy within 3 days. Early diagnosis and early vitrectomy are therefore recommended.
\end{abstract}

Keywords: streptococcus endophthalmitis, visual outcomes, predictive factors

\section{Introduction}

Streptococcus is a virulent Gram-positive bacterium causing severe infectious endophthalmitis. ${ }^{1}$ It is the common cause in delayed-onset bleb-related endophthalmitis and infection following intravitreal injection. ${ }^{2-5}$ It is also a common causative organism in endogenous endophthalmitis, infections following cataract surgery, and ocular trauma. ${ }^{1,6-8}$ Streptococcal endophthalmitis is usually a devastating eye disease. Despite aggressive treatment of the infection, visual outcomes are generally poor. ${ }^{1-9}$ Kuriyan et $\mathrm{al}^{8}$ studied 63 cases of streptococcus endophthalmitis over an 11-year period and found that the most common clinical settings were bleb-associated (27\%), after intravitreal injection (25\%) and after cataract surgery (21\%). All patients received intravitreal antibiotics and $22 \%$ of the patients underwent pars plana vitrectomy (PPV). Visual outcomes were generally poor with only $25 \%$ having best-corrected visual
Correspondence: Yosanan Yospaiboon KKU Eye Center, Department of Ophthalmology, Faculty of Medicine, Khon Kaen University, 123 Mitraparb Highway, Khon Kaen 40000, Thailand Tel +66 43348383

Email yosanan@kku.ac.th
Clinical Ophthalmology 20I8:12 859-864 Dovepress f 10 http://dx,doi.org/10.214710pTHS161217 (c) (1) (-) 2018 Yospaiboon et al. This work is published and licensed by Dove Medical Press Limited. The full terms of this license are available at https.//www.dovepress.com/terms.php C. hereby accept the Terms. Non-commercial uses of the work are permitted without any further permission from Dove Medical Press Limited, provided the work is properly attributed. For permission for commercial use of this work, please see paragraphs 4.2 and 5 of our Terms (https://www.dovepress.com/terms.php). 
acuity (BCVA) of $20 / 400$ or better and $25 \%$ of the patients had their eyes removed by operations, either evisceration or enucleation. ${ }^{8}$ Kurniawan et $\mathrm{al}^{9}$ studied 101 cases of streptococcus endophthalmitis over a 15 -year period and found that $87.1 \%$ of the infection occurred postoperatively, and cataract surgery was the most commonly performed operation. Almost all patients had initial intravitreal antibiotics, and $30.7 \%$ of the patients underwent vitrectomy. Final vision was 20/100 or better in only $23.3 \%$, whereas the majority of the patients had poor visual outcomes; $19.8 \%$ had no light perception, $14 \%$ had an evisceration, and $10.5 \%$ had an enucleation. ${ }^{9}$ This retrospective study looks at the possible predictive factors that may help ophthalmologists manage this severe intraocular infection. The study analyzes the clinical presentation, microbiological investigation to identify the causative organisms, treatment modalities, and visual outcomes after treatment of patients with culture-proven streptococcal endophthalmitis at a large referral eye center in northeastern Thailand.

\section{Patients and methods}

This study followed the tenets of the Declaration of Helsinki and was approved by the Khon Kaen University Ethics Committee for Human Research. A retrospective medical chart review of all patients with culture-proven endophthalmitis caused by Streptococcus species at KKU Eye Center, Department of Ophthalmology, Faculty of Medicine, Khon Kaen University, Khon Kaen, Thailand from 2012 to 2016 was performed. Patient consent to review their medical records were not required by the Ethics Committee, and the case report forms had no linkage to the patient identities and the researchers respected the privacy of the patients. Inclusion criteria were clinical diagnosis of infectious endophthalmitis, history of prior bleb-associated infection, intraocular injection, ocular injury or intraocular surgery no longer than 6 weeks before, evidence of presumed extraocular sites of infection, medical or surgical treatment at the hospital, and follow-up period of at least 6 weeks. The patients who had a history of corneal disorders or retinal diseases, which might interfere with visual acuity, were excluded from the study. Those who had glaucoma and uncontrolled diabetes mellitus were also excluded. The collected data included age, gender, surgical methods, and BCVA at presentation and after treatment.

Microbiological investigation of vitreous fluid was done in all patients. Undiluted vitreous specimens were obtained by vitreous aspiration through a 23 -gauge needle. The vitreous specimens were inoculated on blood agar, chocolate agar, MacConkey agar, and Sabouraud dextrose agar, as well as in thioglycolate broth and blood culture bottles. The causative organisms were then identified.
The medical treatment consisted of intravitreal injection of vancomycin $(1 \mathrm{mg} / 0.1 \mathrm{~mL})$ and ceftazidime $(2.25 \mathrm{mg} /$ $0.1 \mathrm{~mL}$ ). Intensive topical and systemic vancomycin and ceftazidime were also included. Surgical treatment consisted of complete PPV with intravitreal injection of vancomycin and ceftazidime after the surgery. PPV was indicated in all endophthalmitis patients with the loss of red reflex and substantial vitreous opacity on ultrasonography. In severe cases, PPV combined with silicone oil tamponade was performed depending on the decision of the surgeons. Patients with painful blind eyes were operated on by either evisceration or enucleation.

The primary outcome was possible predictive factors associated with improved visual outcome after treatment. The patients were classified as having "improved" visual outcome when their final BCVA was 1 or more Snellen acuity lines better than initial BCVA. They were classified as "not improved" when final BCVA was stable or worse than initial BCVA. The secondary outcomes were types of infectious endophthalmitis, causative organisms, types of treatment modalities, and rate of eye removal either by evisceration or enucleation.

Statistical analysis was performed using STATA version 10.0 (StataCorp, College Station, TX, USA). The categorical data such as gender, affected eyes, underlying diseases, types of endophthalmitis, treatment procedures, time to surgery, and visual outcomes are shown in numbers and percentages. The numerical data such as numbers of positive cultures and causative organisms are also reported in numbers and percentages. Age is denoted as mean \pm standard deviation and range. Visual outcome after treatment in different patient groups was compared and analyzed using $\chi^{2}$ test and Fisher's exact test. The difference was considered significant when $P$-value was $<0.05$.

\section{Results}

Among 411 patients (417 eyes) diagnosed with infectious endophthalmitis during the 6-year study period, 45 (10.95\%) patients (45 eyes) were culture positive for Streptococcus spp.; 24 (53.33\%) males and 21 (46.67\%) females. Twentyfour $(53.33 \%)$ right eyes and $21(46.67 \%)$ left eyes were affected. The mean age of the patients was 55.2 \pm 21.3 ; range 5-89 years. Nine $(20 \%)$ patients had a history of diabetes mellitus and $10(22.22 \%)$ patients had a history of hypertension. The types of endophthalmitis seen in this study are demonstrated in Table 1. Sixteen patients (35.56\%) developed endophthalmitis following intraocular surgery, whereas 9 patients $(20 \%)$ had infection after ocular trauma. Among the other causes, endogenous endophthalmitis was found in 
Table I Types of endophthalmitis

\begin{tabular}{lll}
\hline $\begin{array}{l}\text { Types of } \\
\text { endophthalmitis }\end{array}$ & Number & Percentage \\
\hline Postoperative & 16 & 35.56 \\
Posttraumatic & 9 & 20.00 \\
Endogenous & 7 & 15.56 \\
Keratitis-associated & 2 & 4.44 \\
Bleb-related & 1 & 2.22 \\
Undetermined & 10 & 22.22 \\
Total & 45 & 100 \\
\hline
\end{tabular}

7 patients (15.56\%), keratitis-associated disease in 2 patients (4.44\%), and bleb-related infection in 1 patient $(2.22 \%)$. Of 16 postoperative endophthalmitis cases, 13 developed after phacoemulsification, 2 after extraocular cataract extraction, and 1 after combined penetrating keratoplasty with cataract surgery. All 9 patients with posttraumatic endophthalmitis developed infection after penetrating ocular injuries from twigs (4) and nails (4) and by bird pecking (1).

Visual acuity at presentation is demonstrated in Table 2 . Most patients (95.56\%) presented with hand motion (55.56\%), light perception (28.89\%), or no light perception (11.11\%). There was only 1 patient who presented with counting finger and another patient who presented with visual acuity of $4 / 60$. After treatment, most patients (53.33\%) had visual acuity of no light perception. There were only 5 patients $(11.1 \%)$ who achieved visual acuity of $6 / 60$ or better. Two of these 5 patients achieved final visual acuities of $6 / 6$.

The data on specific causative organisms are summarized in Table 3. The 3 most common isolates were Streptococcus pneumoniae (44.44\%), Group B $\beta$-hemolytic Streptococcus (26.68\%), and Streptococcus viridans (20\%). As can be seen in Table 3, S. pneumoniae was the most common causative organism in the postoperative type, whereas Group B $\beta$-hemolytic Streptococcus was the leading cause

Table 2 BCVA at presentation and after treatment

\begin{tabular}{lll}
\hline Visual acuity & $\begin{array}{l}\text { At presentation, } \\
\mathbf{n}(\%)\end{array}$ & $\begin{array}{l}\text { After treatment, } \\
\mathbf{n}(\%)\end{array}$ \\
\hline No light perception & $5(1 \mathrm{I} .1 \mathrm{I})$ & $24(53.33)$ \\
Light perception & $\mathrm{I} 3(28.89)$ & $5(\mathrm{II} . \mathrm{II})$ \\
Hand motion & $25(55.56)$ & $8(17.78)$ \\
Counting finger & $\mathrm{I}(2.22)$ & $2(4.44)$ \\
$2 / 60$ & - & $\mathrm{I}(2.22)$ \\
$4 / 60$ & $\mathrm{I}(2.22)$ & - \\
$6 / 60$ & - & $\mathrm{I}(2.22)$ \\
$6 / 24$ & - & $\mathrm{I}(2.22)$ \\
$6 / 12$ & - & $\mathrm{I}(2.22)$ \\
$6 / 6$ & - & $2(4.44)$ \\
Total & $45(100)$ & $45(100)$ \\
\hline
\end{tabular}

Abbreviation: BCVA, best-corrected visual acuity. in endogenous type. S. viridans was commonly identified in patients with endophthalmitis following ocular trauma and intraocular surgery.

The treatment modalities are listed in Table 4. Most patients $(62.22 \%)$ were treated by surgical interventions, either PPV with intravitreal antibiotics or PPV with intravitreal antibiotics and silicone oil tamponade. It was noted that there was a high rate of evisceration or enucleation (33.33\%) in the current study.

Table 5 demonstrates the visual outcomes after treatment, and it can be seen that these improved in 9 patients (20\%). There were only 5 of 9 patients who had final BCVA of $6 / 60$ or better; most patients had poor visual outcomes (Table 2). There were 24 patients $(53.33 \%)$ who had no light perception, and 15 of 24 patients underwent eye removal, either by evisceration or enucleation (Table 4).

Factors associated with improved visual outcome are also demonstrated in Table 5. It was noted that posttraumatic endophthalmitis had slightly more improved visual outcomes than other types, but the difference was not statistically significant $(P=0.65)$. For causative organisms, although endophthalmitis caused by $S$. pneumoniae seemed to have the most unfavorable visual outcomes when compared to those infected with other Streptococcus spp., there was no statistically significant difference $(P=0.247)$. Regarding treatment modalities, medical treatment and PPV with antibiotics demonstrated more improved visual outcomes than PPV with antibiotics and silicone oil tamponade, but the difference was not statistically significant $(P=0.072)$. For time to surgery, patients who underwent early vitrectomy ( $<3$ days) had more improved visual outcomes than those who underwent delayed surgery, and the difference was statistically significant $(P<0.001)$. All 6 patients in the early vitrectomy group demonstrated improved visual outcomes, and 5 of these 6 patients had final BCVA of $6 / 60$ or better.

\section{Discussion}

In the present study, streptococcal endophthalmitis accounted for $10.95 \%$ of patients with infectious endophthalmitis. This is similar to the study of Kurniawan et $\mathrm{al}^{9}$ that reported a rate of streptococcal endophthalmitis of $11.8 \%$. The condition is often associated with poor visual prognosis. Only 9 patients $(20 \%)$ in this study had improved vision after treatment. This finding agrees with other previous studies. ${ }^{1-9}$ The 3 most common isolates in this study were S. pneumoniae (44.44\%), Group B $\beta$-hemolytic Streptococcus (26.68\%), and S. viridans (20\%). Kuriyan et $\mathrm{al}^{8}$ also reported these 3 common isolates 
Table 3 Causative microorganisms evidenced by culture

\begin{tabular}{|c|c|c|c|c|c|c|c|}
\hline Organisms & Postoperative & $\begin{array}{l}\text { Post } \\
\text { trauma }\end{array}$ & Endogenous & $\begin{array}{l}\text { Post } \\
\text { keratitis }\end{array}$ & Bleb-related & Undetermined & $\mathbf{N}(\%)$ \\
\hline Streptococcus pneumoniae & 11 & 4 & - & 2 & - & 3 & $20(44.44)$ \\
\hline Group B $\beta$-hemolytic & 1 & - & 5 & - & - & 6 & $12(26.68)$ \\
\hline \multicolumn{8}{|l|}{ Streptococcus } \\
\hline Streptococcus viridians & 4 & 5 & - & - & - & - & $9(20.00)$ \\
\hline Streptococcus suis & - & - & 1 & - & - & 1 & $2(4.44)$ \\
\hline$\beta$-nonhemolytic Streptococcus & - & - & 1 & - & - & - & $\mathrm{I}(2.22)$ \\
\hline Streptococcus spp. & - & - & - & - & 1 & - & I (2.22) \\
\hline Total & 16 & 9 & 7 & 2 & I & 10 & $45(100)$ \\
\hline
\end{tabular}

as causative organisms in their study, but with a different percentage, that is, S. viridans (71\%), S. pneumoniae (21\%), and Group B $\beta$-hemolytic Streptococcus (8\%). These 3 common organisms are all normal flora in the conjunctiva that can be a source of endophthalmitis after intraocular surgery, intraocular injection, or ocular trauma. ${ }^{10}$ However, they were much less common than coagulase-negative Staphylococcus, which was the most common flora in the conjunctiva. ${ }^{10}$

In this study, the most common type of endophthalmitis was the postoperative type. Most patients (35.56\%) developed infection following intraocular surgery, and S. pneumoniae $(11 / 16,68.75 \%)$ was the main causative organism identified in this type. This finding is similar to the results of some previous studies, ${ }^{9,11,12}$ but different from the study of Kuriyan et $\mathrm{al}^{8}$ which reported bleb-associated infection as the most common type. Posttraumatic endophthalmitis was the next most common type (20\%) in the current study, and the 2 main isolates were $S$. viridans $(5 / 9,55.56 \%)$ and $S$. pneumoniae $(4 / 9,44.44 \%)$. In addition, there were 2 eyes that developed mixed infection with $S$. viridans following ocular injuries and had final BCVA of no light perception. These findings were however not consistent with other previous studies which reported that endophthalmitis following ocular trauma was much less common. ${ }^{8,10}$

In the present study, group B Streptococcus was the main organism found in endogenous endophthalmitis $(6 / 7$, $85.71 \%$ ). This also agrees with other previous studies. ${ }^{7,13}$ Three of these 6 patients developed endophthalmitis after

Table 4 Treatment modalities

\begin{tabular}{lll}
\hline Treatment modalities & Number & Percentage \\
\hline Medical treatment & 2 & 4.44 \\
PPV with antibiotics & 16 & 35.56 \\
PPV with antibiotics and silicone oil & 12 & 26.67 \\
Evisceration or enucleation & 15 & 33.33 \\
Total & 45 & 100 \\
\hline
\end{tabular}

Abbreviation: PPV, pars plana vitrectomy. the onset of septic arthritis. Palmar abscess, cellulitis in the right foot, and liver abscess were extraocular sites of infection in 3 other patients. Among the 3 patients with septic arthritis, 2 patients was culture positive for Group B $\beta$-hemolytic Streptococcus and 1 patient was culture positive for Group B $\beta$-nonhemolytic Streptococcus. Three other patients were also positive for Group B $\beta$-hemolytic Streptococcus. Only 2 of 6 patients had improved visual outcome, whereas 4 of 6 patients had worse final vision and 2 of 4 patients underwent eye removal, 1 by enucleation and another by evisceration. These results were in agreement with previous studies which showed that despite intravitreal antibiotics and vitrectomy,

Table 5 Factors associated with improved visual outcome

\begin{tabular}{|c|c|c|c|}
\hline Factors & $\begin{array}{l}\text { Improved, } \\
\text { n (\%) }\end{array}$ & $\begin{array}{l}\text { Not improved, } \\
\text { n (\%) }\end{array}$ & $P$-value \\
\hline \multicolumn{3}{|l|}{ Type of endophthalmitis } & 0.65 \\
\hline Posttraumatic & $3(33.33)$ & $6(66.67)$ & \\
\hline Endogenous & $2(28.57)$ & $5(71.43)$ & \\
\hline Postoperative & $2(12.5)$ & I4 (87.5) & \\
\hline Keratitis associated & 0 & $2(100)$ & \\
\hline Bleb-related & 0 & $\mathrm{I}(100)$ & \\
\hline Undetermined & $2(20)$ & $8(80)$ & \\
\hline \multicolumn{3}{|l|}{ Causative organisms } & 0.247 \\
\hline$\beta$-nonhemolytic & $\mathrm{I}(100)$ & 0 & \\
\hline \multicolumn{4}{|l|}{ Streptococcus } \\
\hline Streptococcus suis & I (50) & I (50) & \\
\hline Streptococcus viridans & $2(25)$ & $6(75)$ & \\
\hline Group B $\beta$-hemolytic & $2(16.67)$ & $10(83.33)$ & \\
\hline \multicolumn{4}{|l|}{ Streptococcus } \\
\hline $\begin{array}{l}\text { Streptococcus } \\
\text { pneumoniae }\end{array}$ & $3(15)$ & $17(85)$ & \\
\hline \multicolumn{3}{|l|}{ Treatment modalities } & 0.072 \\
\hline Medical & I (50) & I (50) & \\
\hline PPV with antibiotics & $7(43.75)$ & $9(56.25)$ & \\
\hline $\begin{array}{l}\text { PPV with antibiotics } \\
\text { and silicone oil }\end{array}$ & I (8.33) & II (9I.67) & \\
\hline \multicolumn{3}{|l|}{ Time to surgery } & $<0.001$ \\
\hline 0-3 days & $6(100)$ & 0 & \\
\hline More than 3 days & $3(13.04)$ & $20(86.96)$ & \\
\hline
\end{tabular}

Abbreviation: PPV, pars plana vitrectomy. 
the visual prognosis in patients with group B Streptococcus endogenous endophthalmitis is generally poor. ${ }^{7-9,13}$

PPV and intravitreal antibiotics, either with or without silicone oil tamponade, were the main treatment modalities used in this study. Silicone oil has antimicrobial properties, can prevent bacterial penetration, has compartmentalization effect to make intravitreal antibiotic concentration higher than usual (PPV without silicone oil), and can prevent post-operative retinal detachment. ${ }^{14,15}$ Previous studies also showed the benefit of vitrectomy with silicone oil tamponade over vitrectomy alone in the case of severe endophthalmitis. ${ }^{16-19}$ However, visual outcome in this study was improved in only 8 of 28 eyes (28.57\%). Although medical treatment and PPV with antibiotics (Table 5) had more improved visual outcomes than PPV with antibiotics and silicone oil tamponade, this actually could not be compared because of the difference in severity of endophthalmitis. Medical treatment was generally used in patients with a mild degree of infection, whereas silicone oil was used in severe and complicated cases. Moreover, evisceration and enucleation were done in $33.33 \%$ of patients with streptococcal endophthalmitis. This high rate of eye removal was similar to other previous studies that reported a range of eye removal from $24.7 \%$ to $30.5 \% .^{8,9,12}$ Although these findings indicated that patients with streptococcal endophthalmitis had poor visual outcomes, it was demonstrated in this study that patients who underwent early vitrectomy $<3$ days showed the most favorable visual outcomes when compared to those who underwent delayed surgery. Kurniawan et al, ${ }^{9}$ however, reported that early vitrectomy within 48 hours of presentation had no correlation with visual outcome. This discrepancy may be attributed to different methods of analysis. This study compared the number of patients with improved visual outcomes between early and delayed vitrectomy, whereas Kurniawan et $\mathrm{al}^{9}$ compared the number of patients with poor final vision (visual acuity of $6 / 60$ or worse) between patients who had undergone vitrectomy within 48 hours and those with delayed vitrectomy. Also, this study used improved visual outcomes, which indicated that final vision gained 1 or more line of Snellen acuity compared with initial vision, whereas Kurniawan et $\mathrm{al}^{9}$ used only final visual acuity, which was not related to visual acuity at presentation.

\section{Conclusion}

This study confirms the results of other previous studies that streptococcal endophthalmitis is a devastating eye disease and is often associated with poor visual prognosis. Only 9 patients $(20 \%)$ in this study showed improved visual outcomes after treatment, and rate of eye removal was high. Early vitrectomy, done within 3 days, was associated with the most favorable visual outcomes. Early diagnosis and early vitrectomy are therefore recommended. Rapid microbiological investigation such as polymerase chain reaction can help ophthalmologists identify causative organisms early and make earlier treatment decisions, as well as advise the patients on their visual prognosis.

The strength of this study is that all patients in the study had infectious endophthalmitis with culture-proven Streptococcus spp.. An obvious limitation is that it is a retrospective study. There might be some important data missing. Another limitation is that the number of patients in each subgroup might be too small to observe statistically significant differences and conclusions. This study however gives some interesting information for further study in the future. It is recommended that further prospective studies with larger sample sizes be pursued.

\section{Acknowledgments}

The authors thank Dr Kaewjai Thepsuthammarat, Clinical Epidemiology Unit, Faculty of Medicine, Khon Kaen University, for statistical analysis. This study was supported by an invitation research grant from the Faculty of Medicine, Khon Kaen University, Thailand. This study was presented in part at the 39th Academic Meeting of the Royal College of Ophthalmologists of Thailand, July 26-28, 2017, Bangkok, Thailand.

\section{Disclosure}

The authors report no conflicts of interest in this work.

\section{References}

1. Endophthalmitis Vitrectomy Study Group. Results of the Endophthalmitis Vitrectomy Study: a randomized trial of immediate vitrectomy and of intravenous antibiotics for the treatment of postoperative bacterial endophthalmitis. Arch Ophthalmol. 1995;113(12):1479-1496.

2. Leng T, Miller D, Flynn HW Jr, Jacobs DJ, Gedde SJ. Delayed-onset bleb-associated endophthalmitis (1996-2008): causative organisms and visual acuity outcomes. Retina. 2011;31(2):344-352.

3. Jacobs DJ, Leng T, Flynn HW Jr, Shi W, Miller D, Gedde SJ. Delayedonset bleb-associated endophthalmitis: presentation and outcome by culture result. Clin Ophthalmol. 2011;5:739-744.

4. Yamamoto T, Kuwayama Y, Kano K, Sawada A, Shoji N; Study Group for the Japan Glaucoma Society Survey of Bleb-related infection. Clinical features of bleb-related infection: a 5-year survey in Japan. Acta Ophthalmol. 2013;91(7):619-624.

5. McCannel CA. Meta-analysis of endophthalmitis after intravitreal injection of anti-vascular endothelial growth factor agents: causative organisms and possible prevention strategies. Retina. 2011;31(4): $654-661$. 
6. Lalwani GA, Flynn HW Jr, Scott IU, et al. Acute-onset endophthalmitis after clear corneal cataract surgery (1996-2005). Ophthalmology. 2008; 115(3):473-476.

7. Jackson TL, Eykin SJ, Graham EM, Stanford MR. Endogenous bacterial endophthalmitis: a 17-year prospective series and review of 267 reported case. Surv Ophthalmol. 2003;48:403-423.

8. Kuriyan AE, Weiss KD, Flynn HW, et al. Endophthalmitis caused by streptococcal species: clinical settings, microbiology, management, and outcomes. Am J Ophthalmol. 2014;154(4):774-780.

9. Kurniawan ED, Rocke JR, Sandhu SS, Allen PJ. Predictors of visual outcome and role of early vitrectomy in streptococcal endophthalmitis. Clin Exp Ophthalmol. Epub September 26, 2017.

10. Sthapit PR, Tuladhar NR. Conjunctival flora of normal human eye. JSM Ophthalmol. 2014;2(2):1021.

11. Miller JJ, Scott IU, Flynn HW Jr, Smiddy WE, Corey RP, Miller D. Endophthalmitis caused by Streptococcus pneumoniae. Am J Ophthalmol. 2004;138(2):231-236.

12. Soriano F, Perez-Trallero E, Pallares R, et al. Streptococcus pneumoniae endophthalmitis: a study of 36 cases with special reference to antibiotic resistance and treatment option. Clin Microbiol Infect. 2006;12(6): 519-526.
13. Lee SY, Chee SP. Group B Streptococcus endogenous endophthalmitis: case report and review of the literature. Ophthalmology. 2002; 109(10):1879-1886.

14. Ozdamar A, Aras C, Ozturk R, Akin E, Karacorlu M, Ercikan C. In vitro antimicrobial activity of silicone oil against endophthalmitis-causing agents. Retina. 1999;19(2):122-126.

15. Azad R, Ravi K, Taiwar D, Rajpal, Kumar N. Pars plana vitrectomy with or without silicone oil endotamponade in post-traumatic endophthalmitis. Graefes Arch Clin Exp Ophthalmol. 2003;241(6):478-483.

16. Lin H, Ling S, Liu Z, Zhong X, Chen W. Preventive scleral buckling and silicone oil tamponade are important for posttraumatic endophthalmitis successfully managed with vitrectomy. Ophthalmologica. 2011; 226(4):214-219.

17. Nowroozzadeth $\mathrm{M}$. The equivocal role of silicone oil in the treatment of traumatic endophthalmitis. Eur J Ophthalmol. 2009;19(3):496-497.

18. Yan H, Lu Y, Yu J, et al. Silicone oil in the surgical treatment of traumatic endophthalmitis. Eur J Ophthalmol. 2008;18(5):680-684.

19. Kaynak S, Oner FH, Koçak N, Cingil G. Surgical management of postoperative endophthalmitis: comparison of 2 techniques. J Cataract Refract Surg. 2003;29(5):966-969.
Clinical Ophthalmology

\section{Publish your work in this journal}

Clinical Ophthalmology is an international, peer-reviewed journal covering all subspecialties within ophthalmology. Key topics include: Optometry; Visual science; Pharmacology and drug therapy in eye diseases; Basic Sciences; Primary and Secondary eye care; Patient Safety and Quality of Care Improvements. This journal is indexed on

\section{Dovepress}

PubMed Central and CAS, and is the official journal of The Society of Clinical Ophthalmology (SCO). The manuscript management system is completely online and includes a very quick and fair peer-review system, which is all easy to use. Visit http://www.dovepress.com/ testimonials.php to read real quotes from published authors. 